\title{
Influence of Prognostic Factors on Survival in Locally Advanced Non-Small Cell Lung Cancer Patients Treated with Combination of Chemoradiotherapy
}

\section{Simonida Crvenkova}

University Clinic of Radiotherapy and Oncology, Faculty of Medicine, Skopje, Macedonia

*Corresponding author: Crvenkova S, University Clinic of Radiotherapy and Oncology, Faculty of Medicine, Skopje, Macedonia, Tel: +38970338687; E-mail: simonidac@hotmail.com

Received date: Oct 13, 2014, Accepted date: Nov 13, 2014, Publication date: Nov 17, 2014

Copyright: (c) 2014 Crvenkova S. This is an open-access article distributed under the terms of the Creative Commons Attribution License, which permits unrestricted use, distribution, and reproduction in any medium, provided the original author and source are credited.

\begin{abstract}
According to the literature, performance status, stage-tumor dimension and nodal status, weight loss, were the most important prognostic factors for survival in patients with locally advanced non-small cell lung cancer. To evaluate the treatment results and prognostic variables in our patients, study of 85 patients was randomly assigned to one of the two treatment arms. In the sequential arm, 45 patients had previously received sequential chemotherapy with 4 cycles of and etoposide followed by conformal radiotherapy (RT). In the second concurrent group, 40 patients received concomitant chemotherapy of cisplatine and etoposide and conformal RT, followed by two cycles of consolidation chemotherapy of carboplatine and etoposide. We described all phases of the conformal three dimensional (3-D) RT.
\end{abstract}

From October 2005 to April 2008, 85 patients were enrolled. Eight patients were not eligible, seven had stage IV and one patient had pleural effusion. They were all initially considered to have stage IIIB disease. The median survival was 13 months for the patients in the sequential arm and 19 months for those in the concurrent treatment arm. The differences were statistically significant (log-rank test $p=0.0039$ ). The disease-free survival was 9 months in the sequential arm and 16 months in the concurrent treatment group. The differences were statistically significant (log-rank test $p=0.0023$ ).

We found that the following prognostic factors significantly influenced the survival in lung cancer patients treated with conservative method: (1) age: $p<0.05$; (2) Performance status: $p<0.001$; (3) Weight loss: $p<0.001$; (4) Tumor dimension: $p<0.05$; (5) Nodal involvement: $p<0.05$

Conclusions: Given the higher toxicity in the concurrent-consolidation schedule, it should be reserved for patients younger than 70 years, having good performance status and minimal weight loss. Also we highly recommend precisely define the stage of disease and the prognostic factors in lung cancer patients for giving better treatment.

Keywords: Prognostic factors; Performance status; Stage; Weight loss; Radiotherapy; Sequential and concurrent chemoradiotherapy

\section{Introduction}

Lung cancer remains a worldwide epidemic. Approximately 1.2 million people die from lung cancer each year. NSCLC represents over $80 \%$ of all lung cancers and $60 \%$ to $70 \%$ of the patients with NSCLC suffer from stage III or IV disease. In the late 1980s, radiotherapy was the standard treatment for these patients [1]. Randomized trials showed that combination of chemoradiotherapy was superior to radiotherapy alone [2]. Many chemotherapeutic agents active in NSCLC possess radiosensitizing properties, thereby improving the probability of local control. In addition, chemotherapy administered concurrently with thoracic radiation may act systemically and potentially eradicate distant micrometastases. Several studies showed the feasibility of the cisplatin-etoposide combination plus radiotherapy for patients with stage III disease [3].

Successfully tailored therapy in lung cancer patients requires to define the prognostic factors. Prognostic factors are defined as characteristics of patients and stage, before starting the treatment.
Analyzing these characteristics provides the opportunity to select patients in different groups and choose the best treatment modality for the selected group. They are also important to evaluate the results of treatments and to compare the results of different clinical studies [4].

Primary end point of this study was to evaluate the treatment results and the prognostic variables in our patients treated with sequential and concurrent chemoradiotherapy.

\section{Material and Methods}

In our study 110 patients with NSCLC stage IIIA and IIIB were analyzed at the University Clinic of Radiotherapy and Oncology in Skopje in the period from October 2005 to April 2008. Only 85 patients were eligible for this study, aged between 18 and 70 years, had an Eastern Cooperative Oncology Group (ECOG) Score $\leq 1$, and had $\leq 10 \%$ weight loss in the period of 3 months before inclusion. They have previously untreated histological or cytological proven NSCLC, unrespectable stage IIIA-N2 disease, or stage IIIB disease without pleural effusion. Stage IIIB disease was assigned either by $\mathrm{N} 3$ (contralateral mediastinal or supraclavicular nodes) or by T4 from invasion of mediastinal structures. Following prognostic factors were 
Citation: Crvenkova S (2014) Influence of Prognostic Factors on Survival in Locally Advanced Non-Small Cell Lung Cancer Patients Treated with Combination of Chemoradiotherapy . J Nucl Med Radiat Ther 6: 200. doi:10.4172/2155-9619.1000200

Page 2 of 6

evaluated: aged (18-43, 44-55, 56-70); histological type (squamous, adenocarcinoma large cell carcinoma and unspecified type); performance status (PS) according to ECOG Score $\leq 1$, weight loss in the period of 3 months before inclusion $(<5 \%, 5-10 \%)$; lymph nodes involvement and tumor dimension $(\leq 5 \mathrm{~cm},>5 \mathrm{~cm}$ and unmeasurment because atelectasis, pneumonitis); symptoms duration before treatment ( $<3$ months, 3-6 months, $>6$ months); and hemoglobin level $(<120 \mathrm{~g} / \mathrm{l}, \geq 120 \mathrm{~g} / \mathrm{l})$.

The following laboratory values were required: leucocytes $\geq$ $1.5 \times 10^{3} / 1$, platelets $\geq 100 \times 10 / 1$, AST and ALT $\leq 2 \times$ the upper limit of the reference range. Ineligibility criteria were as follows: uncontrolled infection, or fever over $38^{\circ} \mathrm{C}$, unstable cardiovascular disease and previous malignancy.

Before enrollment, the patients gave their full medical histories and underwent clinical examination with assessment of performance status. In the sequential arm, responses were assessed 8 weeks after the end of radiotherapy. In the concurrent arm, responses were assessed 8 weeks after the end of the consolidation chemotherapy. Imaging studies $\mathrm{x}$-ray and/or computed tomography (CT) could be repeated at all times when clinically indicated. Complete and partial responses were based on RECIST criteria. Toxicity was graded according to RTOG/EORTC criteria. Follow-up visits were conducted every 2 months during the first year and, afterwards, every 3 months. Patients were randomly assigned to receive sequential or concurrent therapy. In the sequential arm, 45 patients received four cycles of chemotherapy. They were administered first, consisting of carboplatin (AUC $\times$ 6) on day 1 and etoposide on days $1-3$, repeated every 3 weeks. The radiotherapy began 4 weeks after the fourth cycle of chemotherapy administration. Chemotherapy and radiotherapy began simultaneously in concurrent arm, including 40 patients. The radiotherapy schedule was identical to that in the sequential arm. The first cycle with cisplatin $30 \mathrm{mg} / \mathrm{m}^{2}$ and etoposide $100 \mathrm{mg} / \mathrm{m}^{2}$ was administered on days 1 to 3 and the second 3-days cycle was administered the last 3 days of radiotherapy. After 4 weeks of concurrent chemoradiotherapy schedule, two cycles of consolidation chemotherapy began, consisting of carboplatine (AUC x 6) and etoposide $100 \mathrm{mg} / \mathrm{m}^{2}$ on day 1 to 3 .

Conformal radiotherapy at both arms consisted of $60 \mathrm{~Gy}$ in 30 fractions of 2 Gy per fraction, for 5 days a week given over a period of 6 weeks. Treatment planning CT was required to define the gross tumor volume (GTV). Each patient was positioned in an immobilization device-wing board in the treatment position on a flat table. CT slices with $5 \mathrm{~mm}$ thickness were obtained, starting from cricoid cartilage and extending inferiorly to the level of the L1 vertebral body. The GTV, clinical target volume (CTV), planning target volume (PTV) and normal organs were outlined on all CT slices. The normal tissues that were contoured included both lungs (as the total lung volume), heart, spinal cord and esophagus. The CTV included the entire GTV plus $0.7 \mathrm{~cm}$ and the PTV included CTV plus another $0.7 \mathrm{~cm}$ adding margin. PTV44 was treated with parallelopposed anterior-posterior fields and PTV60 was treated with any combination of fields depends of spinal cord constrain. If radiotherapy had to be delayed for more than 7 days, the patient was withdrawn from the study. Patients with evidence of progression at any time were removed from the study, but continued to be evaluated for survival and toxicity. Survival and interval to recurrence or progression were measured from the date of the first treatment session.

\section{Results}

From November 2005 to April 2008, 85 patients were enrolled. Eight patients were not eligible, seven had stage IV and one patient had pleural effusion. All these were initially considered to have stage IIIB disease. The characteristics of 85 patients are listed in Table 1.

\begin{tabular}{|l|l|l|l|}
\hline Patient characteristics & Concurrent chemoradiotherapy arm & $\begin{array}{l}\text { Sequential } \\
\text { chemoradiotherapy arm }\end{array}$ & $\mathbf{p}$ \\
\hline No of eligible pts & 40 & 45 & \\
\hline Age & & 1 & 13 \\
\hline $18-43$ & 20 & 32 & 0.13 \\
\hline $44-55$ & 20 & & \\
\hline $56-70$ & & 40 & 5 \\
\hline Sex & 35 & 5 & 23 \\
\hline Male & 5 & 22 & 0.98 \\
\hline Female & 26 & 22 & 0.19 \\
\hline Performance status & 14 & & \\
\hline 0 & 26 & & \\
\hline 1 & 14 & & \\
\hline Weight loss & & & \\
\hline$<5 \%$ & & & \\
\hline $5-10 \%$ & Histology & & \\
\hline
\end{tabular}


Citation: Crvenkova S (2014) Influence of Prognostic Factors on Survival in Locally Advanced Non-Small Cell Lung Cancer Patients Treated with Combination of Chemoradiotherapy . J Nucl Med Radiat Ther 6: 200. doi:10.4172/2155-9619.1000200

Page 3 of 6

\begin{tabular}{|c|c|c|c|}
\hline Squamous cell & 22 & 34 & \\
\hline Adenocarcinoma & 10 & 6 & 0.26 \\
\hline Large cell & 3 & 2 & \\
\hline Unspecified & 5 & 3 & \\
\hline \multicolumn{4}{|l|}{$\mathrm{N}$ status } \\
\hline N1 & 12 & 15 & \\
\hline N2 & 25 & 27 & 0.93 \\
\hline N3 & 3 & 3 & \\
\hline Tumor $5 \mathrm{sm}$ & 14 & 18 & 0.38 \\
\hline Tumor $>5 \mathrm{sm}$ & 27 & 20 & \\
\hline \multicolumn{4}{|l|}{ Hemoglobin } \\
\hline$<120 \mathrm{~g} / \mathrm{l}$ & 11 & 19 & \\
\hline$\geq 120 \mathrm{~g} / \mathrm{l}$ & 29 & 26 & 0.15 \\
\hline \multicolumn{4}{|c|}{ Duration of symptoms } \\
\hline \multicolumn{4}{|l|}{$<3$ months } \\
\hline 3-6 months & & & 0.29 \\
\hline$>6$ months & & & \\
\hline
\end{tabular}

Table 1: Patients characteristic.

Survival was analyzed until Mart 2010. The median survival was 13 months in the sequential arm (95\%CI 10.2-15.7), and 19 months in the concurrent treatment arm (95\%CI 13.6-24.3). The differences were statistically significant (log-rank test $\mathrm{p}=0.0039$ ), (Figure 1 ). The 1 -year, 2 -year and 3 -year survival rates were $74 \%, 36 \%$ and $27 \%$ in the concurrent arm and $52 \%, 14 \%$ and $7.1 \%$ in the sequential arm, respectively.

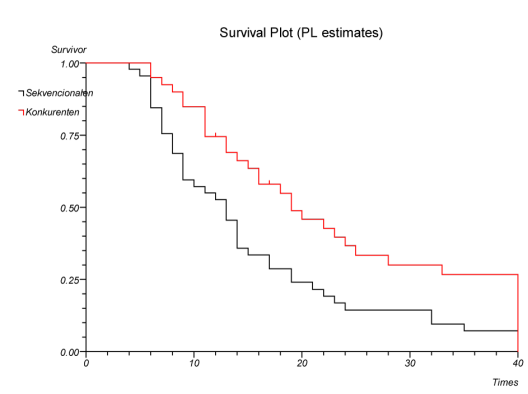

Figure 1: Overall survival according the treatment.

Disease-free survival for the concurrent arm was 16 months $(95 \%$ CI 12.7-19.2), and for the sequential arm was 9 months (95\% CI 5.812.16). The differences were statistically significant (log-rank test $\mathrm{p}=0.0023$ Figure 2).

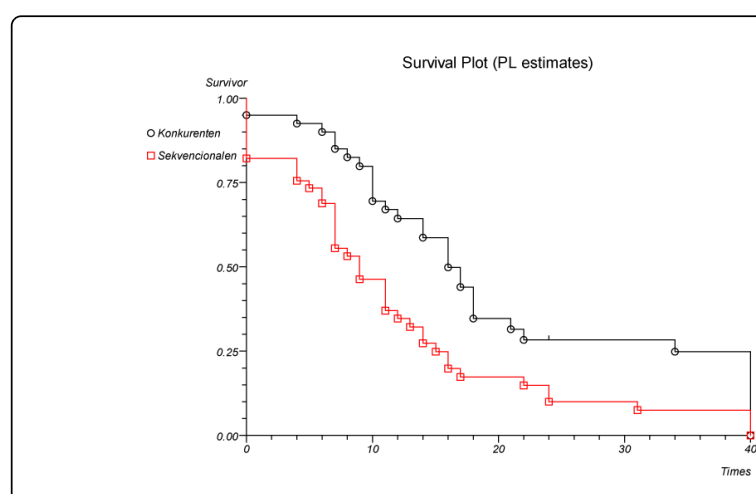

Figure 2: Disease-free survival according the treatment.

One of the aims of this study was to evaluate the prognostic factors on survival. The analysis was not performed according to the treatment modality, sequential or concurrent, because the two groups were homogeneous without significant differences between them.

Most patients in our study were between 44-55 and 56-70 years of age. The youngest patient was 38 years old and the oldest was 70 years. Average age was 58.2 years ( $\mathrm{SD} \pm 6.68$ years). Patients aged between 44 and 55 had median survival of 14 months (95\% CI 10.15-17.84), significantly better than the patients between 56 and 70 years of age, with median survival time of 10 months (95\% CI 4.3-15.6) ( $\mathrm{p}<0.05)$.

As we expected, performance status, according to ECOG criteria, has important influence on survival. Overall survival for patients with 
Citation: Crvenkova S (2014) Influence of Prognostic Factors on Survival in Locally Advanced Non-Small Cell Lung Cancer Patients Treated with

ECOG 0 was 19 months, significantly better than 10 months for patients with ECOG 1 status $(\mathrm{p}<0.001)$, (Figure 3).

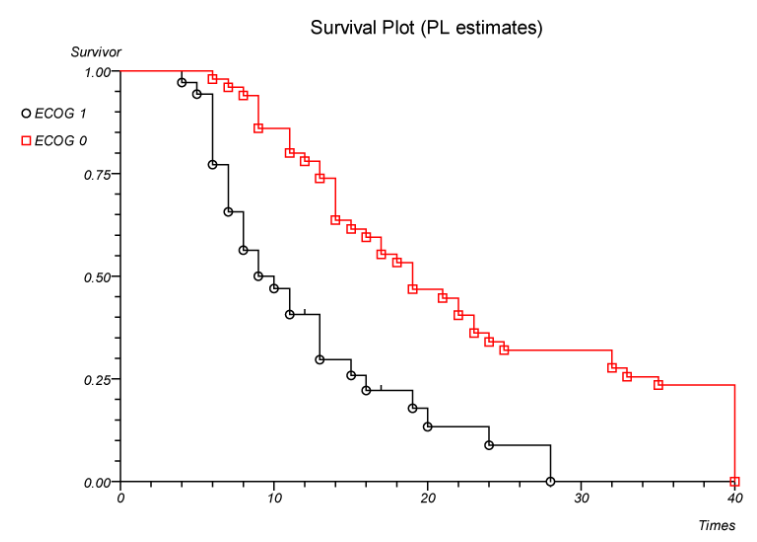

Figure 3: ECOG status and survival.

Another prognostic factor influencing the survival was weight loss in the period of 3 months before inclusion. Median survival in patients group with weight loss under 5\% was 16 months (95\% CI 12.2-19.7) and was, in statistical terms, significantly better than 7 months $(95 \%$ CI 5.5-11.3) in patients with weight loss between $5 \%$ and $10 \%$ $(\mathrm{p}<0.001)$

Tumor dimension was also an important prognostic factor with statistical influence on survival $(\mathrm{p}<0.001)$. Patients with tumor dimension under $5 \mathrm{~cm}$ in size have median survival of 20 months (95\% CI 13.6-26.3), compared with survival of 13 months at patients with tumors dimension over $5 \mathrm{~cm}$ in size (95\% CI 9.8-16.1) and 9 months (95\% CI 6.1-13.8) at unmeasured tumors (Figure 4).

\begin{tabular}{|l|l|l|l|l|l|}
\hline Hemoglobin level & $\begin{array}{l}\text { average } \\
\text { (months) }\end{array}$ & $\begin{array}{l}12 \\
\text { months (\%) }\end{array}$ & $\begin{array}{l}24 \\
\text { months } \\
(\%)\end{array}$ & $\begin{array}{l}36 \\
\text { months } \\
(\%)\end{array}$ & total \\
\hline$<120 \mathrm{~g} / \mathrm{l}$ & 9 & $44 \%$ & $14 \%$ & $0 \%$ & $16 \%$ \\
\hline$\geq 120 \mathrm{~g} / \mathrm{l}$ & 17 & $72 \%$ & $29 \%$ & $30(35 \%)$ & $55(65 \%)$ \\
\hline & $\mathrm{p}=0.06$ & & $85(100 \%)$ \\
\hline
\end{tabular}

Table 2: Survival according hemoglobin level.

In our study, histological type of lung tumors, gender and duration of symptoms before starting the treatment, were prognostics factors without any significant influence on survival.

\section{Discussion}

Our study compared sequential and concurrent chemoradiation therapy in locally advanced NSCLC. We found more benefit of concurrent therapy than in the previously listed trials, in terms of overall and disease-free survival (19 vs $13 ; 16$ vs 9 months), and the difference was significant with log-rank test. When our study was

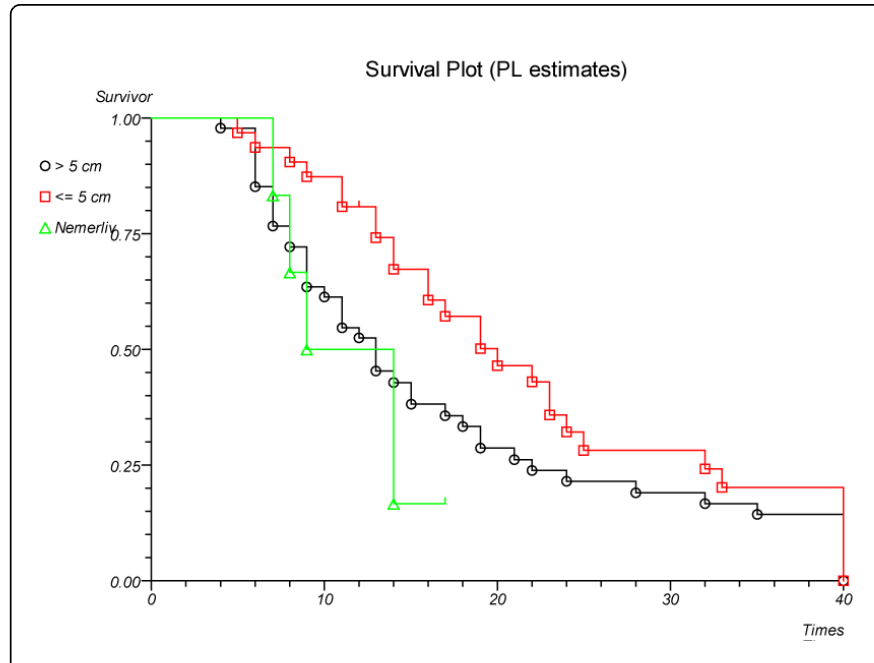

Figure 4: Survival according the tumor dimension.

Lymph nodes involvements also have statistical influence on survival in lung cancer patients treating with chemoradiotherapy. Patients with N1 lymph nodes involvement live the longest median of 20 months (95\% CI 11.1 months to 32.8 months), compared to 13 months (95\% CI 9.6-16.3) at patients with N2 involvements and 7 months (95\% CI $5.8-8.1$ ) at those patients with $\mathrm{N} 3$ involvement $(\mathrm{p}<0.001)$.

Another parameter we analyzed in this study was hemoglobin level in patients' blood. Patients with hemoglobin level under $120 \mathrm{~g} / \mathrm{l} \mathrm{had}$ survival average of 9 months (95\% CI 6.5 -11.4), and patients with hemoglobin level over $120 \mathrm{~g} / \mathrm{l}$ had survival of approximately 17 months (95\% CI 12.9-21.1). We also account 1-year, 2-years and treeyears survival rate for each hemoglobin level. The differences between two groups of patients were high, but still not statistically significant $(\mathrm{p}=0.06)$, (Table 2$)$.

designed, the cisplatin-etoposide combination was mostly used concurrently with radiotherapy. Consolidation chemotherapy with two cycles of carboplatin-etoposide was administered in the concurrent arm to balance the dose of platinum based chemotherapy in the two arms. This consolidation chemotherapy administered after concurrent chemoradiotherapy seems promising in terms of survival, as shown in the Southwest Oncology Group (SWOG) S9504 and Locally Advanced Multimodality Protocol (LAMP) studies [5,6]. Although many reports have analyzed prognostic factors in metastatic NSCLC, fewer have focused on stage III disease [7]. In 1995 Jeremic and Shibamoto [8] evaluated prognostic factors among 169 stage III 
NSCLC patients treated with hyperfarctionated thoracic RT 6468 Gy with or without etoposide and/or carboplatin chemotherapy. In their multivariate analysis, Karnofsky PS $\geq 80 \%$, weight loss $\leq 5 \%$, lower disease stage, younger age $<60$ years and female gender were are associated with an improved survival. Wigren [9] used database of 210 patients to develop a prognostic index of prognostic factors to stratify the patient population into six different groups with significantly differing median survival times.

Sealy et al. [10] informed that elderly patients with inoperable lung cancer manifested local disease recurrence, while younger patient showed distant dissemination, proven in our study. According to the most authors, gender did not influence survival. But Coy et al. [11] reported that 5-years survival time for female patients treated with curative radiotherapy was longer than in man. We did not confirm this in our study.

According to our study, histology type of lung cancer did not influence the survival, confirm the same from the literature. Patients with adenocarcinoma have median survival time for all stages of disease, 45 mounts, and patients with squamous histology median survival of 44 mounts, statistically without differences [12,13].

We have confirmed in our study that tumor dimension was an important factor influencing the survival. Patz et al informed that that there was only correlation between tumor dimension and local disease control, without influence on the survival [14].

The most important prognostic factor according to the literature was the performance status with literature report for the first time by Zelen in 1973 [15]. The RTOG [16] analyzed 1592 patients with locally advanced NSCLC treated between 1983 and 1987 with thoracic RT alone. The single most important factor was Karnofsky PS with the cut-off point being $70 \%$. This report, as the report of Wigren is limited in nowadays current value, as the current standard of care in patients with good PS is combined chemoradiation. There was another trials that combined chemotherapy with RT and confirmed that PS is important prognostic factor [17]. We also confirmed that the baseline performance status had statistically significant influence on survival.

In our study, overall survival in patients' group with weight loss under $5 \%$ was 16 months and was significantly better, in statistical terms, than 7 months in patients' group with weight loss between 5 and $10 \%$. Data from the literature confirmed our conclusion $[18,19]$.

The observation regarding the impact of baseline hemoglobin is of interest. Anemia has been identificated as significant predictor of survival in advanced, metastatic NSCLC [20]. Socinski et al. in combined modality trials of the CLGB, clearly suggests improved survival in patients with hemoglobin values of $>12 \mathrm{~g} / \mathrm{l}$ [21]. In our study we did not confirm this but there was strong difference between two groups $(\mathrm{p}=0.06)$. Unfortunately, this analysis did not evaluate changes in hemoglobin during therapy and what impact this may have on survival. According our study, further investigation for maintaining hemoglobin level was necessary, due to optimal cell oxygenation is important factor for local tumor control, and indirect for survival.

\section{Conclusion}

We highly recommend precisely define the stage of disease and the prognostic factors in lung cancer patients and hope that for precise selected patient group possibility for better treatment will be higher.
Given the high toxicity in the concurrent-consolidation schedule, it should be reserved for patients younger than 70 years, having good performance status and minimal weight loss. In our study, the doselimiting toxicity, esophagitis was reduced by performing conformal radiotherapy.

\section{References}

1. Le Chevalier T, Arriagada R, Quoix E, Ruffie P, Martin M, et al. (1991) Radiotherapy alone versus combined chemotherapy and radiotherapy in nonresectable non-small-cell lung cancer: first analysis of a randomized trial in 353 patients. J Natl Cancer Inst 83: 417-423.

2. [No authors listed] (1995) Chemotherapy in non-small cell lung cancer: a meta-analysis using updated data on individual patients from 52 randomised clinical trials. Non-small Cell Lung Cancer Collaborative Group. BMJ 311: 899-909.

3. Friess GG, Baikadi M, Harvey WH (1987) Concurrent cisplatin and etoposide with radiotherapy in locally advanced non-small cell lung cancer. Cancer Treat Rep 71: 681-684.

4. Stanley KE (1980) Prognostic factors for survival in patients with inoperable lung cancer. J Natl Cancer Inst 65: 25-32.

5. Gandara DR, Chansky K, Albain KS, Leigh BR, Gaspar LE, et al. (2003) Consolidation docetaxel after concurrent chemoradiotherapy in stage IIIB non-small-cell lung cancer: phase II Southwest Oncology Group Study S9504. J Clin Oncol 21: 2004-2010.

6. Choy H, Curran WJ, Scot CB (2002) Preliminary report of locally Advanced Multimodality Protocol (LAMP): ACR 427: A randomized phase II study of three chemo-radiation regimens with paclitaxel, carboplatin and thoracic radiation (TRT) for patients with locally advanced NSCLC (LA-NSCLC). Proc Am Soc Clin Oncol 21: 291a (abstr 1160).

7. Socinski MA (2001) Diagnosis and Tretment of Lung Cancer: An Evidence-based Guide for Practicing Clinician. Philadelphia PA WB Sauders: 307-325.

8. Jeremic B, Shibamoto Y (1995) Pre-treatment prognostic factors in patients with stage III non-small cell lung cancer treated with hyperfractionated radiation therapy with or without concurrent chemotherapy. Lung Cancer 13: 21-30.

9. Wigren $\mathrm{T}$ (1997) Confirmation of a prognostic index for patients with inoperable non-small cell lung cancer. Radiother Oncol 44: 9-15.

10. Sealy R, Lagakos S, Barkley T, Ryall R, Tucker RD, et al. (1982) Radiotherapy of regional epidermoid carcinoma of the lung: a study in fractionation. Cancer 49: 1338-1345.

11. Coy P, Kennelly GM (1980) The role of curative radiotherapy in the treatment of lung cancer. Cancer 45: 698-702.

12. Chansky K, Sculier JP, Crowley JJ, Giroux D, Van Meerbeeck J, et al. (2009) The International Association for the Study of Lung Cancer Staging Project: prognostic factors and pathologic TNM stage in surgically managed non-small cell lung cancer. J Thorac Oncol 4: 792-801.

13. Travis WD, Colby TV, Corrin B, Shimosato Y, Brambilla E, et al. (1999) Histological Typing of Lung Tumors. Geneva Switzerland World Health Organization.

14. Patz EF Jr, Rossi S, Harpole DH Jr, Herndon JE, Goodman PC (2000) Correlation of tumor size and survival in patients with stage IA nonsmall cell lung cancer. Chest 117: 1568-1571.

15. Zelen M (1973) Keynote address on biostatistics and data retrieval. Cancer Chemother Rep 3 4: 31-42.

16. Scott C, Sause WT, Byhardt R, Marcial V, Pajak TF, et al. (1997) Recursive partitioning analysis of 1592 patients on four Radiation Therapy Oncology Group studies in inoperable non-small cell lung cancer. Lung Cancer 17 Suppl 1: S59-74.

17. Dillman RO, Herndon J, Seagren SL, Eaton WL Jr, Green MR (1996) Improved survival in stage III non-small-cell lung cancer: seven-year 
Citation: Crvenkova S (2014) Influence of Prognostic Factors on Survival in Locally Advanced Non-Small Cell Lung Cancer Patients Treated with Combination of Chemoradiotherapy . J Nucl Med Radiat Ther 6: 200. doi:10.4172/2155-9619.1000200

Page 6 of 6

follow-up of cancer and leukemia group B (CALGB) 8433 trial. J Nat Cancer Inst 88: 1210-1215.

18. Janssen-Heijnen ML, Gatta G, Forman D, Capocaccia R, Coebergh JW (1998) Variation in survival of patients with lung cancer in Europe, 1985-1989. EUROCARE Working Group. Eur J Cancer 34: 2191-2196.

19. Merrill RM, Henson DE, Barnes M Travis WD, Colby TV, Corrin B, et al (1999) Survival among patients with carcinoma of the lung. Chest 166: 697-703.
20. Caro JJ, Salas M, Ward A, Goss G (2001) Anemia as an independent prognostic factor for survival in patients with cancer: a systemic, quantitative review. Cancer 91: 2214-2221.

21. Socinski MA, Zhang C, Herndon JE 2nd, Dillman RO, Clamon G, et al. (2004) Combined modality trials of the Cancer and Leukemia Group B in stage III non-small-cell lung cancer: analysis of factors influencing survival and toxicity. Ann Oncol 15: 1033-1041. 